\title{
Concentração de fenol em resíduos de laboratórios de análises clínicas
}

\author{
Phenol concentration evaluation in clinical analysis laboratory waste
}

\author{
Maria Clarinda de Araujo Almeida'; Andréa de A. Morégula²; \\ Paulo César L. Marrocos ${ }^{3}$; Soraya M. M. de Souza ${ }^{4}$; Marcel Tavares de Farias ${ }^{5}$
}

\begin{abstract}
unitermos resumo
Resíduos

Introdução: Durante décadas, os laboratórios foram considerados pouco impactantes ao meio ambiente. Tiveram essa comodidade abalada devido à mobilização da sociedade civil que vem exigindo

Fenol mudanças. A Agência Nacional de Vigilância Sanitária (ANVISA) implementou a Resolução da Diretoria

Meio ambiente Colegiada (RDC) n $n^{\circ} 306$, de 7 de dezembro de 2004, criando o Plano de Gerenciamento de Resíduos Saúde de Serviços de Saúde (PGRSS), devido ao fato de o gerenciamento de resíduos sólidos não urbanos ser de responsabilidade do gerador desde sua geração até sua disposição final. Objetivos: A expectativa desta pesquisa foi avaliar as concentrações de fenol no momento de descarte na pia, investigar processos que minimizem os riscos ao ambiente e à saúde pública e validar a técnica para extração do fenol a partir dos resíduos gerados pelo setor da bioquímica; substância sólida, tóxica, corrosiva, constituinte dos reativos utilizados nas análises de colesterol. A legislação brasileira permite que um efluente de descarte seja de $0,5 \mathrm{\mu g} \mathrm{ml}^{-1}$. Material e métodos: Para tanto, utilizou-se a técnica de cromatografia gasosa. Resultados e conclusão: Essa técnica foi capaz de qualificar e quantificar o fenol tanto nas amostras do laboratório semiautomatizado quanto automatizado, havendo decréscimo e, em seguida, constância nas concentrações de fenol como resultado.
\end{abstract}

abstract

Introduction: During decades, laboratories were deemed to produce low environmental impact. This has changed dramatically due to current social environmental demands. ANVISA implemented RDC $n^{\circ} 306$ from December 7, 2004, creating the Health Care Waste Management Plan (PGRSS), which states that producers of non-urban solid waste are accountable for its generation and ultimate disposal. Objectives: To evaluate phenol concentrations at wastewater discharge. To investigate processes that minimize environmental and public health risks. To validate procedure for phenol extraction from waste generated by the biochemist area, once it is a toxic solid, corrosive chemical substance, commonly found in reagents used in cholesterol analyses. According to our Brazilian Legislation, the discharge effluent emission standard is $0.5 \mu \mathrm{g} \mathrm{ml}^{-1}$. Material and methods: It was used gas chromatography. Results and conclusion: It was possible to qualify and quantify phenol concentrations in both semi-automated and automated laboratory samples and the results revealed a decrease and subsequent stability in phenol concentrations. key words

Wastewaters

Phenol

Environment

Health

1. Mestra pelo Programa Regional de Pós-graduação em Desenvolvimento Regional e Meio Ambiente da Universidade Estadual de Santa Cruz (PRODEMA/UESC) ; farmacêutica bioquímica do Laboratório de Análises Clínicas POLLLAB Ltda.

2. Doutora em Física; professora titular da Universidade Estadual de Santa Cruz (UESC).

3. Doutor em Fitotecnia (Produção Vegetal); professor adjunto da UESC; servidor público ou celetista da Comissão Executiva do Plano da Lavoura Cacaueira (CEPLAC).

4. Graduada em Química Analítica Industrial; servidora púbica da CEPLAC.

5. Mestre em Toxicologia; professor de Toxicologia Ceral e Analítica da União Metropolitana de Educação e Cultura (UNIME), Lauro de Freitas, Bahia. 


\section{Introdução}

Resíduos de serviços de saúde (RSS) são resíduos sólidos e semissólidos resultantes de atividades hospitalares e demais estabelecimentos prestadores de serviços de saúde. São fonte de risco à saúde humana e ao meio ambiente devido ao aparecimento de vetores de disseminação de doenças, perigosos tanto para a equipe de trabalhadores dos estabelecimentos de saúde quanto para os pacientes ${ }^{(11)}$.

A Agência Nacional de Vigilância Sanitária (ANVISA) implementou a Resolução da Diretoria Colegiada (RDC) $n^{\circ} 302$, de 13 de abril de 2005(3), que regulamentou o funcionamento técnico dos laboratórios e determinou a necessidade de se implantar o Plano de Gerenciamento de Resíduos de Serviços de Saúde (PGRSS), atendendo aos requisitos da $\mathrm{RDC} \mathrm{n}^{\circ} 306$, de 7 de dezembro de $2004^{(4)}$, em que os mesmos são geradores de resíduos sólidos e semissólidos dos tipos A, B, C, D e E, tendo o último sido inserido por meio da Resolução 33, de 25 de fevereiro de $2003^{(1)}$.

Infelizmente, ainda hoje, prevalece a cultura do descarte na pia em função das dificuldades de se implantarem regras de controle e fiscalização eficientes aos pequenos geradores de RSS ${ }^{(10)}$, incluindo substâncias químicas do grupo B - resíduos com riscos químicos - descartadas muitas vezes de forma aleatória e diretamente na rede de esgotos. $\mathrm{O}$ setor de bioquímica de qualquer laboratório utiliza para os exames de colesterol reativos químicos do tipo B7, Resolução $\mathrm{n}^{\circ} 33^{(1)}$ adaptada. Sendo o fenol constituinte desse reativo, em sua metabolização podemos encontrar concentrações tóxicas, corrosivas e deletérias tanto para a saúde pública quanto para o meio ambiente.

De acordo com a legislação brasileira em vigor, um efluente de descarte de qualquer fonte poluidora deve ter concentração máxima de fenóis de $0,5 \mu \mathrm{g} \mathrm{m}^{-1(8)}$. Quando jogado no solo, esse material é biodegradável e tem meia-vida de um a 10 dias. Já em contato com a água, sua meia-vida é de 10 a 30 dias, sendo uma substância tóxica para a vida aquática. Bentur et al.(2) estimaram a meia-vida biológica ( $\mathrm{t} 1 / 2$ ) para o fenol de 13,86 horas. Por sua vez, $\mathrm{CHEMINFO}^{(7)}$ acredita que a meia-vida biológica é de 12 horas, em média, e sua eliminação é feita por urina, fezes, saliva e suor, sendo a urina a principal via de excreção, podendo ser degradada por fotólise e ter meia-vida de menos de um dia.

Quando acontecem emissões de efluentes, ocorrem alterações químicas na composição dos compostos. Observam-se compostos químico-tóxicos, metais pesados com alterações na cor, $\mathrm{pH}$, turbidez, odor, aumento na temperatura, provocando desequilíbrio ecológico do corpo receptor, e nutrientes em excesso (eutrofização), além dos sólidos dissolvidos e em suspensão(14).

Quando inalado, o fenol causa irritação em olhos e nariz, afeta o sistema respiratório, provoca convulsões e pode levar à morte. Quando em contato com os olhos, provoca severas irritações e pode causar cegueira; quando em contato com a pele, pode causar irritações severas e queimaduras; e quando ingerido, pode provocar gangrena e ulcerações no sistema digestivo( ${ }^{(9)}$.

Em se tratando de fenol, não foram encontrados na literatura trabalhos referentes à sua extração em resíduos. Dessa forma, para a realização deste trabalho, optou-se por fazer uma adaptação da metodologia utilizada por Peixe ${ }^{(12)}$, que realizou estudos sobre a concentração de fenol na urina de trabalhadores e no ar do ambiente de trabalho. Utilizouse a técnica da cromatografia gasosa (CG) para análise, na qual, para se obter melhor resolução na determinação de fenol, foram utilizadas as seguintes condições cromatográficas: coluna HP com $15 \mathrm{~m}$ de comprimento, diâmetro de $0,53 \mathrm{~mm}$ e tamanho de película de $1,5 \mu \mathrm{m}$.

\section{Objetivos}

Avaliar se os teores do fenol provenientes de laboratórios de análises clínicas no momento do descarte nas pias estão dentro dos valores permitidos pela legislação; identificar processos que minimizem os riscos ao ambiente e à saúde pública, por meio da utilização de menores quantidades de reativos ou do tempo de repouso dos resíduos gerados, para posterior descarte; validar técnica para extração e determinação do fenol.

\section{Material e métodos}

\section{Solventes, reagentes e padrões}

Para a realização da metodologia proposta foram utilizados: metanol grau cromatográfico (Merck), ácido clorídrico P.A. (Synth) e éter etílico P.A. (Synth). Foram utilizados fenol (padrão de fenol P.A. $500 \mathrm{~g}$ Riedel-de-Haën ${ }^{\circledR}$ ) e ortocresol 500 mg (Fluka) nitrobenzeno (Riedel-de-Haën ${ }^{\circledast}$ ) para realização das análises.

\section{Cromatografia gasosa}

O método adotado foi a CG, método físico-químico de separação dos componentes de uma mistura. Para tanto, 
foi usado um cromatógrafo VARIAN-3.800 Saturno, com detector de ionização de chama (CG/FID) sob temperatura de $250^{\circ} \mathrm{C}$. A coluna utilizada foi VARIAN de Metil Silicone, $15 \mathrm{~m} \times 0,53 \mathrm{~mm} \times 0,15 \mu \mathrm{m}$, com temperatura inicial de $60^{\circ} \mathrm{C} / 2 \mathrm{~min}$, rate de $10^{\circ} \mathrm{C} / \mathrm{min}$ e final de $120^{\circ} \mathrm{C} / 2 \mathrm{~min}$. Injetor: $200^{\circ} \mathrm{C}$. Fluxo de gás de arraste (hélio): $8 \mathrm{ml} / \mathrm{min}$. Modo de injeção: Split ratio 1/10, sendo injetados $2 \mu \mathrm{l}$ das amostras extraídas.

\section{Coleta das amostras}

A coleta das amostras para análise foi realizada a partir de resíduos gerados por um laboratório semiautomatizado, de rotina, onde os exames são feitos com utilização de $1 \mathrm{ml}$ de reativo por reação, e por um laboratório automatizado, de hospital, onde os exames são feitos usando-se $0,3 \mathrm{ml}$ de reativo. As amostras foram coletadas no final do dia de trabalho, contendo a totalidade de todos os reativos utilizados naquele dia.

Os resíduos químicos analisados foram oriundos do setor da bioquímica, muito rico no uso de diversas substâncias químicas, entre elas o fenol, constituinte do reativo para determinação de colesterol livre e que, no mercado, é encontrado em diversas concentrações. Nos dois serviços, o reativo utilizado é da mesma marca, com mesma concentração.

Foram colhidas duas amostras, sendo uma do laboratório semiautomatizado e a outra de um automatizado, nos dias 3 e 4 de novembro de 2008 , respectivamente. Houve um período de tempo de 0,2,22, 23, 25, 30, 65 dias decorridos entre a coleta e o congelamento. Após os dias 22, 23, 25, 30 e 65, as extrações e análises aconteceram pelo método 3, diferindo das citadas anteriormente, realizadas pelo método 1. Foram feitos recálculos das concentrações para serem analisadas e discutidas na dissertação de mestrado. As amostras foram mantidas em frascos fechados, em local fresco, seco, ventilado, até o congelamento. Os períodos de tempo foram necessários para se observar a degradação do fenol.

\section{Preparação das amostras}

Foi utilizado o procedimento descrito por Peixe ${ }^{(12)} \mathrm{com}$ adaptações. No trabalho citado, foram adicionados $5 \mathrm{ml}$ de urina (controle negativo), $50 \mu \mathrm{l}$ do padrão interno (PI) e 1 $\mathrm{ml}$ de ácido clorídrico $(\mathrm{HCl}) 37 \%$ e foi feito o aquecimento em estufa a $95^{\circ} \mathrm{C}$ por 1,5 hora. Posteriormente, adicionaram-se $5 \mathrm{ml}$ de éter etílico e $1 \mathrm{~g}$ de cloreto de sódio $(\mathrm{NaCl})$ e agitou-se a concentração em uma mesa agitadora por
10 minutos. Assim, coletaram-se $3 \mathrm{ml}$ da fase orgânica e $2 \mu$ foram injetados no cromatógrafo (CG/FID) ${ }^{(12)}$. O procedimento pode visualizado na Figura 1.

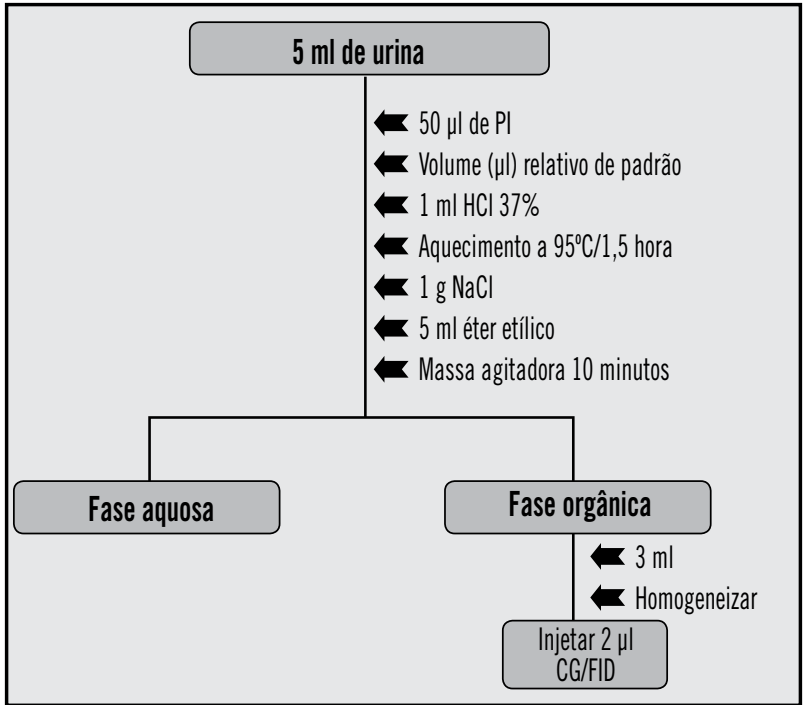

Figura 1 - Representação esquemática do protocolo para extração de fenol em urina descrito por Peixe $e^{(16)}$

PI: padrão interno; CG/FID: cromatografia gasosa com detector de ionização de chama.

A adaptação da metodologia citada na Figura 1 foi necessária, uma vez que a matriz da amostra utilizada não era urina, mas resíduos do setor de bioquímica de laboratórios semiautomatizado e automatizado. Várias tentativas de extração foram efetuadas para se chegar a uma concentração de volumes e substâncias adequadas à extração e à quantificação do fenol, tendo sido realizado procedimento utilizando-se a substância nitrobenzeno como PI.

Adequação à metodologia proposta por Peixe ${ }^{(12)}$ : aumento do volume da amostra em relação à adaptação anterior do PI (elevação de sua concentração), redução do volume de $\mathrm{HCl}$, agitação em vortex, redução de temperatura e tempo de aquecimento, homogeneização durante 1 minuto após adição do éter etílico e, em seguida, após a separação da fase orgânica, esta é acondicionada em frasco âmbar para posterior retirada de $2 \mu \mathrm{l}$ para injeção no cromatógrafo gasoso. A representação esquemática a seguir (Figura 2) mostra-nos a adaptação de metodologia utilizada para as amostras coletadas (3 e 4 de novembro de 2008).

\section{Curva de calibração}

Soluções estoque-mãe de fenol, nitrobenzeno e ortocresol foram preparadas. A de fenol teve concentração de $1 \mu \mathrm{g} \mathrm{ml}^{-1}$ em metanol. As soluções de nitrobenzeno e 


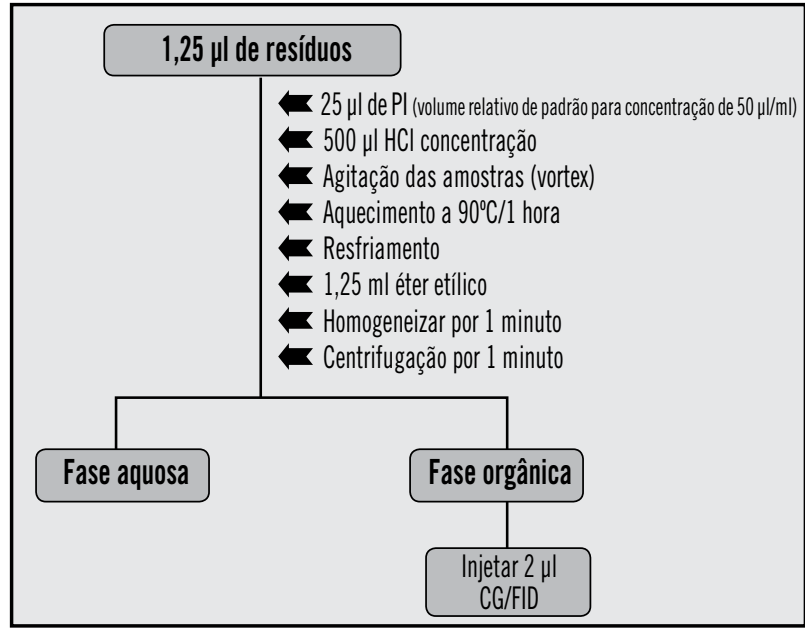

Figura 2 - Representação esquemática para extração de fenol em resíduos de laboratórios, adaptado do protocolo de Peixe ${ }^{(16)}$, utilizada com as amostras colhidas em 3 e 4 de novembro de 2008

PI: padrão interno; CG/FID: cromatografia gasosa com detector de ionização de chama.

orto-cresol tiveram a concentração de $2,5 \mathrm{\mu g} \mathrm{ml}^{-1}$ também em metanol, que evidencia a solução de orto-cresol e fenol.

As análises aconteceram em momentos distintos. Para isso, soluções padrões foram preparadas com o intuito de se conseguir a curva de calibração inerente a cada experimento. A preparação dos padrões denominada método 1 é a concentração de fenol em metanol, com orto-cresol como $\mathrm{Pl}$, preparada para adequação das condições cromatográficas. No método 2, fenol em éter com orto-cresol como $\mathrm{Pl}$; no método 3, fenol em éter com nitrobenzeno como PI. A Tabela a seguir ilustra a relação entre as concentrações do $\mathrm{Pl}$ e fenol utilizados para cada método, evidenciando o coeficiente de determinação $\left(R^{2}\right)$ encontrado.

\section{Validação analítica, linearidade, limite de detecção e quantificação}

Com o objetivo de validar o método analítico, foi utilizada amostra testemunha de resíduo, na qual supostamente não continha o reativo de colesterol que possui fenol em sua constituição, sendo acrescentado fenol e orto-cresol a essa amostra, extraída da mesma maneira e sob as mesmas condições cromatográficas, assegurando a confiabilidade e a aplicabilidade do método.

Foi extraída da mesma maneira que as amostras dos resíduos em estudo, nas mesmas condições, para se concretizar as análises cromatográficas, assegurando qualidade, confiabilidade e aplicabilidade do método.

As extrações foram efetuadas em triplicata a partir das amostras colhidas e seus resultados, comparados com os obtidos com a solução de fenol em metanol, em uma concentração próxima ao limite de quantificação e detecção, observando-se, assim, a possibilidade de serem encontrados picos interferentes nos tempos de retenção do fenol e do orto-cresol (PI).

Uma curva de calibração foi construída nas concentrações de fenol previamente conhecidas, com a finalidade de detectar concentrações crescentes entre 5 e $200 \mu \mathrm{g} / \mathrm{ml}$ de fenol contendo $50 \mu \mathrm{g} / \mathrm{ml}$ do orto-cresol $(\mathrm{Pl})$, obtendo-se um $R^{2}=0,996$. A linearidade das curvas foi analisada por meio das equações da reta e do $R^{2}$, que deve ser superior a $0,98^{(1,5,6,13)}$.

Foi possível verificar a diminuição da concentração de fenol, mediante a observação daquelas encontradas nos resíduos com o passar dos dias, analisando-se a meia-vida.

\section{Resultados e discussão}

Com o objetivo de avaliar se o aparelho estava respondendo bem às condições cromatográficas previamente adotadas pela metodologia proposta e se não sairia nenhuma outra substância no tempo de retenção que não o fenol, foram injetados no aparelho $2 \mu \mathrm{l}$ de éter etílico, em seguida, $2 \mu \mathrm{l}$ de metanol e $2 \mu \mathrm{l}$ da solução mãe de fenol. A Figura 3 mostra-nos cromatogramas da otimização das condições cromatográficas.

Tabela Relação entre as concentrações de PI e fenol utilizadas para cada método

\begin{tabular}{|c|c|c|c|c|c|c|c|c|c|c|}
\hline Métodos & $\mathrm{Pl}$ & $\begin{array}{l}\text { Concentração } \\
\text { de PI ( } \mu g / m l)\end{array}$ & $\begin{array}{c}\text { Padrão } \\
1\end{array}$ & $\begin{array}{l}\text { Padrão } \\
2\end{array}$ & $\begin{array}{l}\text { Padrão } \\
3\end{array}$ & $\begin{array}{c}\text { Padrão } \\
4\end{array}$ & $\begin{array}{l}\text { Padrão } \\
5\end{array}$ & $\begin{array}{l}\text { Padrão } \\
6\end{array}$ & $\begin{array}{c}\text { Padrão } \\
7\end{array}$ & $\mathrm{R}^{2}$ \\
\hline 1 & orto-cresol & 50 & 5 & 10 & 20 & 50 & 100 & 200 & - & 0,996 \\
\hline 2 & orto-cresol & 500 & 5 & 20 & 50 & 100 & 200 & - & - & 0,999 \\
\hline 3 & nitrobenzeno & 250 & 25 & 50 & 75 & 100 & 150 & 200 & 250 & 0,995 \\
\hline
\end{tabular}

Pl: padrão interno; $R^{2}$ : coeficiente de determinação. 
A Figura 4 evidencia picos de fenol e orto-cresol a partir da adição de fenol e orto-cresol à amostra testemunha. Foram realizadas cinco extrações dessa amostra testemunha, que podem ser mais bem observadas nos quatro cromatogramas conseguidos.
A totalidade de exames de colesterol por dia foi bem semelhante em ambos os serviços. Porém, fazendo-se uma comparação com o número de exames realizados diariamente, observou-se que no laboratório automatizado a quantidade de exames é duas a três vezes maior que no

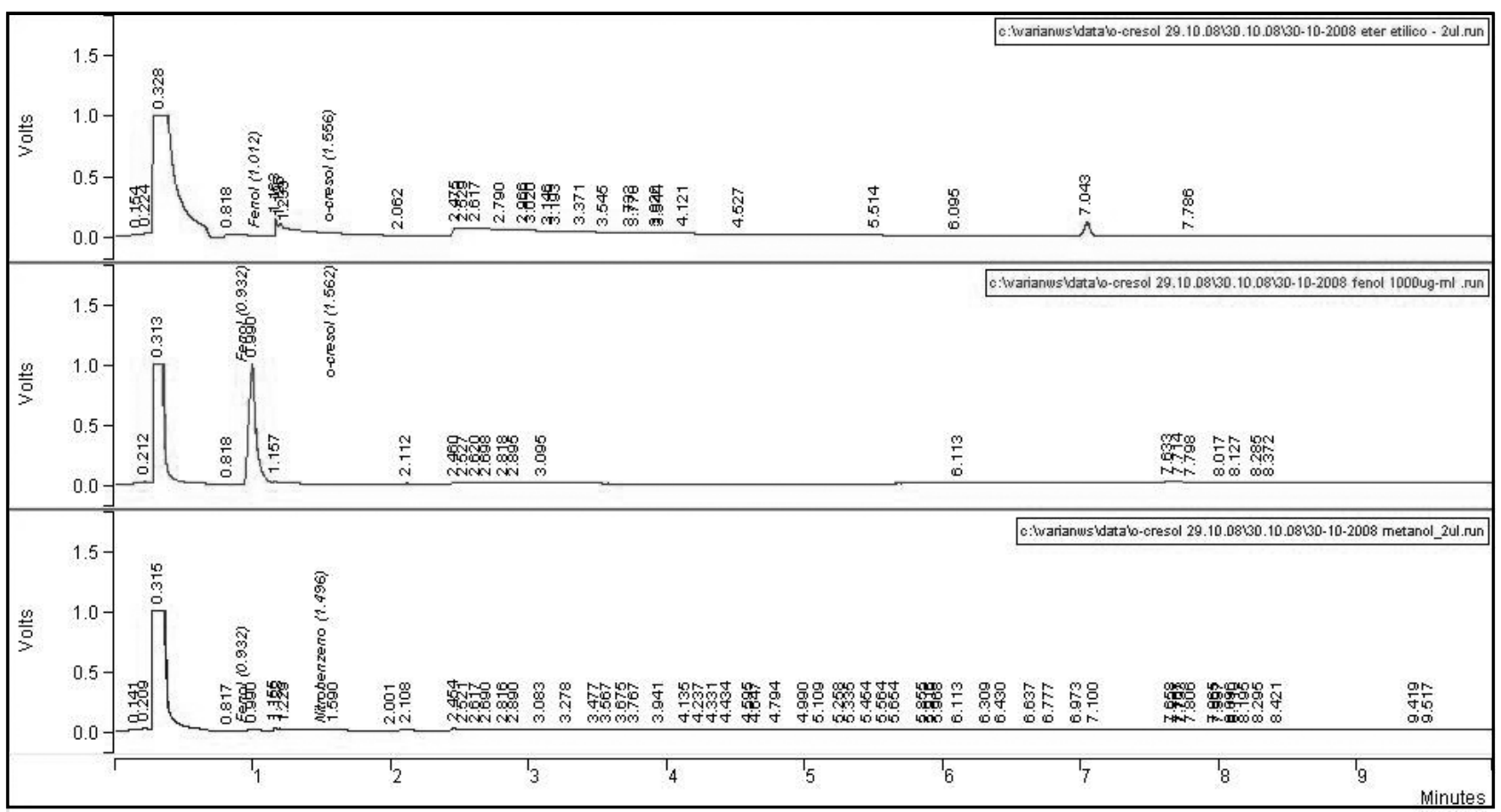

Figura 3 - Cromatogramas para otimização das condições cromatográficas

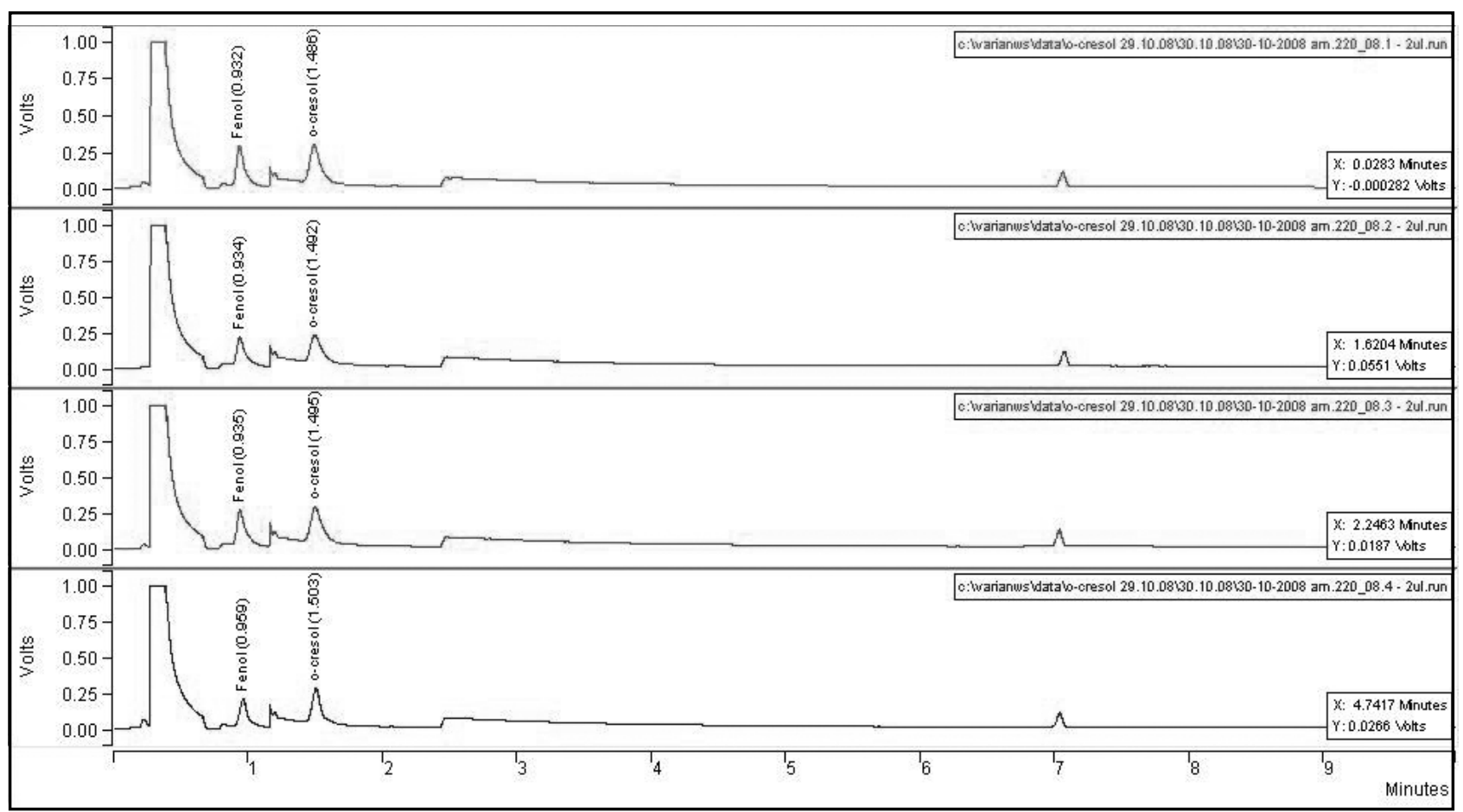

Figura 4 - Amostra testemunha com adição de fenol e orto-cresol 
laboratório semiautomatizado. A variedade de exames realizados no laboratório automatizado também é bem maior que no semiautomatizado.

A partir das amostras colhidas nos dias 3 e 4 de novembro de 2008 , foram determinadas as concentrações de fenol em triplicata, objetivando melhor evidenciar a reprodutibilidade dos resultados do fenol e da variação de sua concentração no decorrer do tempo, além da precisão deles.

Após 48 horas, foi possível observar decréscimo nas concentrações de fenol em ambas as amostras. Nas amostras coletadas no dia 3 de novembro de 2008, foram detectadas concentrações médias de $261 \mu \mathrm{g} \mathrm{ml}^{-1}$, com zero hora em repouso, e observadas concentrações médias de $80,3 \mathrm{\mu g} \mathrm{ml}^{-1}$ após dois dias (Figura 5). Essa concentração é 522 vezes maior que a permitida pela legislação em vigor para descarte $-0,5 \mu \mathrm{g} \mathrm{ml}^{-1}$ no momento do descarte em pia - e 160,6 vezes maior que a permitida, mesmo tendo se passado horas.

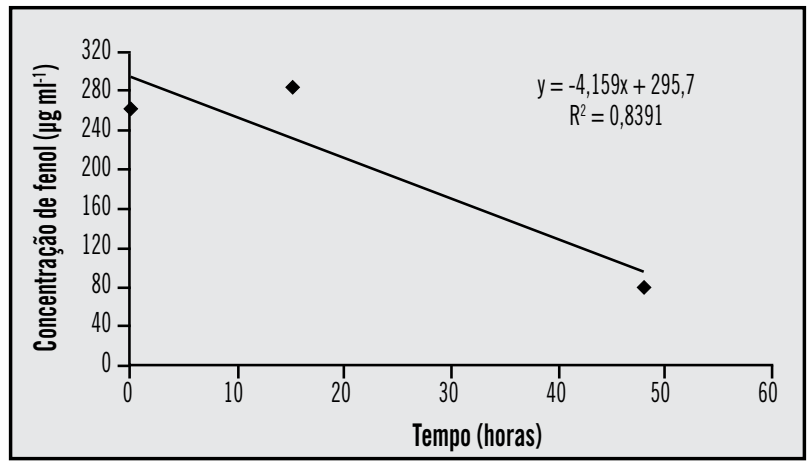

Figura 5 - Relação entre a concentração de fenol e o tempo das amostras do laboratório semiautomatizado coletadas no dia 3 de novembro de 2008 (método 2)

Da mesma maneira, foi possível observar decréscimo nas concentrações de fenol nas amostras coletadas no laboratório automatizado no dia 4 de novembro de 2008, tendo sido detectada queda nas concentrações de fenol no decorrer dos dois dias, partindo as mesmas de uma concentração de $71,28 \mathrm{\mu g} \mathrm{ml}^{-1}$; essa queda chegou a zero nas primeiras 48 horas, como pode ser observado na Figura 6.

As amostras dos resíduos químicos analisados foram mantidas em frascos fechados, em local fresco, seco, ventilado, que mantém penumbra no decorrer do dia (simulação de um possivel armazenamento cotidiano em um laboratório). Levando-se em consideração que o decréscimo das concentrações de fenol após 48 horas também tenha sido em decorrência da meia-vida dessa substância, que é de 30 dias em meio aquoso, elas podem ser descartadas de maneira mais segura tanto para a saúde pública quanto para o meio ambiente, sem custos adicionais para as empresas. As concentrações elevadas, acima do permitido pela legislação, no

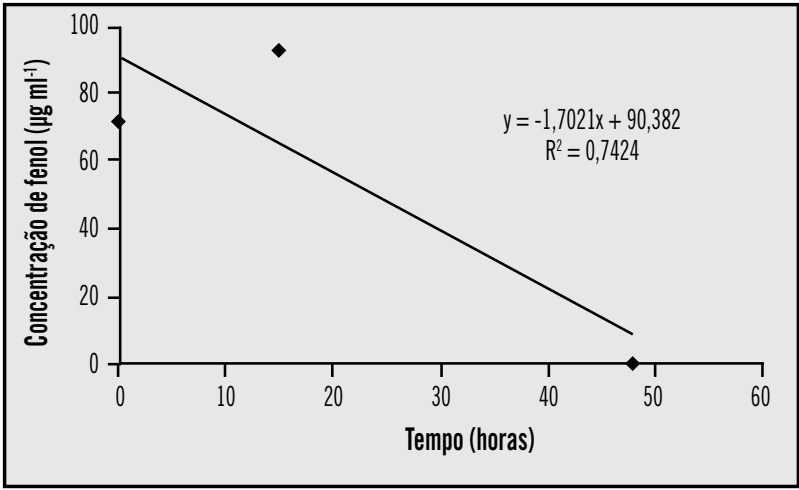

Figura 6 - Relação entre a concentração de fenol e o tempo das amostras do laboratório automatizado coletadas no dia 4 de novembro de 2008 (método 2)

período de 65 dias, podem ter acontecido em decorrência do fenol também ser produto da reação química do colesterol e não apenas de um constituinte do reativo. Lembramos, ainda, que a reação do colesterol é uma das inúmeras reações contidas nos recipientes de armazenagem.

Peixe ${ }^{(12)}$ propunha a utilização de filme com $1,5 \mathrm{~mm}$ de espessura. Na adaptação de seu protocolo, foi retirado o $\mathrm{NaCl}$. Sua adição, no entanto, poderia vir a diminuir a solubilidade de uma substância orgânica na água.

Faz-se necessário que as análises de colesterol aconteçam sem que haja repetições. A partir de um controle de qualidade atuante, o número de repetições diminui, objetivando excelência de resultados por meio de sua reprodutibilidade e sua exatidão, sem que para isso se eleve o número de reações, descartando-se aleatoriamente substâncias poluentes ao meio, agredindo e sendo causa de riscos à saúde pública e ao meio ambiente.

Muito se tem falado sobre os resíduos sólidos de serviços de saúde; muito embora pouco se ouça falar dos resíduos químicos provenientes dos diversos serviços de saúde, em especial os laboratórios clínicos. Seu descarte na rede de esgoto deve proceder de forma consciente, levando-se em consideração que seu descarte diretamente em pia pode causar agravos sérios ao meio ambiente e à saúde pública. A maioria dos serviços, ao descartar seus resíduos, adiciona glutaraldeído ou mesmo água sanitária, inibindo os agentes com riscos biológicos, em detrimento dos riscos químicos e de como minimizá-los, considerando-se os resultados obtidos neste trabalho.

\section{Conclusão}

Os teores de fenol das amostras de ambos os serviços, no momento de descarte em pia, estavam acima do 
permitido pela legislação atual. Foi possível observar a queda da concentração de fenol em amostras de resíduos de laboratórios com o passar de horas (dois dias) em repouso. Sua meia-vida, entretanto, não foi possível ser identificada.
A metodologia de Peixe ${ }^{(12)}$ não nos permite validar essa técnica para extração de fenol em resíduos bioquímicos de laboratórios, devido à complexidade das amostras dos serviços estudados e dos estudos nesta área.

\section{Referências}

1. AGÊNCIA NACIONAL DE VIGILÂNCIA SANITÁRIA. Regulamento técnico para gerenciamento de resíduos de saúde. RDC n 33, de 25 de fevereiro de 2003.

2. BENTUR, Y.; SHOSHANI, A. O.;TABAK, E. Prolonged elimination half-life of phenol after dermal exposure. Journal of Toxicology - Clinical Toxicology, v. 36, n. 7, p. 707-11, 1988.

3. BRASIL. Ministério da Saúde. Agência Nacional de Vigilância Sanitária. Resolução da ANVISA $n^{\circ}$ 302, de 13 de abril de 2005. Diário Oficial de União, Brasília, 15 de abril de 2005.

4. BRASIL, Ministério da Saúde. Agência Nacional de Vigilância Sanitária. Resolução da ANVISA $n^{\circ} 306$, de 7 de dezembro de 2004. Diário Oficial de União, Brasília, 10 de dezembro de 2004.

5. CAUSON, R. Validation of chromatographic methods in biomedical analyses - viewpoint and discussion. Journal of Chromatography B, v. 689, p. 175-80, 1997.

6. CHASIN, A. A. M. et al. Validação de métodos em análises toxicológicas: uma abordagem geral. Revista Brasileira de Toxicologia, v. 11, n. 1, p. 1-6, 1999.

7. CHEMISTRY INFORMATION (CHEMINFO). Phenol. Canadian Centre for Occupational Health and Safety, 2003. $19 \mathrm{p}$.

8. CONSELHO NACIONAL DO MEIO AMBIENTE (Brasil). Resoluções CONAMA 1984-1991. 4. ed. Brasília, DF, 1992.
9. FAENQUIL. Mini-folhetos de Informações de segurança (mini-fis). Disponível em: <http://www.faenquil.br/ gsmt-cipa/3normalizacao/mini_fis/mini_pdf/fenol076. pdf >. Acesso em: 16 maio 2007.

10. GERBASE, A. E. et al. Gerenciamento de resíduos químicos em instituições de ensino e pesquisa. Química Nova, v. 28, p. 3, 2005.

11. MATTOSO, V. D. B. Classificação, quantificação e análise microbiológica dos resíduos de serviço de saúde da Santa Casa de Misericórdia de São Carlos. 1996. Dissertação (Mestrado) - Escola de Engenharia de São Carlos da Universidade de São Paulo, 1996. $90 \mathrm{p}$.

12. PEIXE, T. S. Validação e aplicação de métodos para análise de amostra de fenol em urina de trabalhadores e no ar do ambiente de trabalho. 2006. Dissertação (Mestrado) - Faculdade de Ciências Farmacêuticas da Universidade de São Paulo, 2006.

13. QUEIROZ, S. C. N.; COLLINS, C. H.; JARDIM, I. S. F. Métodos de extração e/ou concentração de compostos encontrados em fluidos biológicos para posterior determinação cromatográfica. Química Nova, v. 1, p. 68-76, 2001.

14. VON SPERLING, M. Princípios do tratamento biológico de águas residuais: introdução à qualidade das águas e ao tratamento de esgoto. 2. ed. Belo Horizonte, MG: DESA-UFMG, 1996. v. 1. 